Check for updates

Cite this: Chem. Sci., 2019, 10, 4782

๑ All publication charges for this article have been paid for by the Royal Society of Chemistry

Received 26th February 2019

Accepted 30th March 2019

DOI: $10.1039 / c 9 s c 00972 h$

rsc.li/chemical-science

\section{Chiral diversification through the assembly of achiral phenylacetylene macrocycles with a two-fold bridge $\uparrow$}

\author{
Ryo Katoono, (iD * Keiichi Kusaka, Yuki Saito, Kazuki Sakamoto and Takanori Suzuki iD
}

\begin{abstract}
We demonstrate so-called "chiral diversification", which is a design strategy to create multiple chiral molecules through the assembly and double-bridging of achiral components. We used phenylacetylene macrocycles (PAMs) as an achiral element. In a molecule, two achiral rings of [6]PAM are stacked one above the other, or bound to each other mechanically. As an alternative, a single enlarged ring of [12] PAM was also assumed to be a doubled form of [6]PAM. In any case, one or two ring(s) are doublybridged by covalent bonds to exert chirality. Through intramolecular two-bond formation, these multiple chiral molecules were obtained as a set of products in one reaction. The dynamic chirality generated in molecules with either two helically-stacked rings of [6]PAM or a single helically-folded ring of [12]PAM was characterized by induced Cotton effects with the aid of an external chiral source. Thus, a chiral structure based on [12]PAM could be demonstrated as the first success. Alternatively, enantiomeric separation was achieved for molecules with two interlocked rings of [6]PAM to show remarkable chiroptical properties.
\end{abstract}

\section{Introduction}

Chirality is a central topic in chemistry. Once an asymmetric center is attached to a molecule, it can be chiral. On the other hand, considerable effort has been exerted to desymmetrize molecules without the use of an asymmetric center. ${ }^{1-8}$ In such molecules, chirality is achieved by the arrangement of achiral components. Especially, the assembly of cyclic components is interesting because multiple forms are possible. The best example would be helical stacking of achiral rings, ${ }^{9}$ where helical chirality is generated when one ring is stacked above the other and twisted in a clockwise or counterclockwise manner with respect to the other ring. Alternatively, mechanically linked achiral rings (catenanes) may be chiral, ${ }^{5,7,10-12}$ when the rings have directionality (topological chirality), ${ }^{5 a, 7,10}$ or simply one ring is relatively tilted with respect to the other ring (mechanical helical chirality). ${ }^{5 a, 12}$ For a case where two rings are further bridged in addition to the mechanical linkage, so called pretzelanes ${ }^{13}$ the further bridging of the mechanically-interlocked rings plays a key role in the characterization of chirality. ${ }^{13 a}$

Department of Chemistry, Faculty of Science, Hokkaido University, Sapporo 060-0810, Japan. E-mail: katoono@sci.hokudai.ac.jp; Fax: +81 11 706-2714; Tel: +81 11 7063396

$\dagger$ Electronic supplementary information (ESI) available: ESI_1: details of energy-minimized structures, NMR and CD spectroscopic data (Fig. S1-S9), and experimental details of new compound synthesis (Scheme S1-S4), ESI_2: copies of ${ }^{1} \mathrm{H}$ and ${ }^{13} \mathrm{C}$ NMR, IR and mass spectra of new compounds. See DOI: 10.1039/c9sc00972h
We have been interested in a design strategy to provide multiple chiral structures through the assembly and doublebridging of achiral components. ${ }^{14-16}$ Here, we used phenylacetylene macrocycles (PAMs) ${ }^{17}$ as achiral components for the creation of multiple chiral molecules. The assembly of two rings provides multiple forms (Scheme 1). Site-specific modification of PAMs ${ }^{18 a}$ would be suitable for bridging of the two rings at arbitrary positions. In the case where two achiral rings of [6] PAM $^{18}$ are stacked and doubly-bridged (Schemes 1 and 2a), helically-chiral structures would be created through the twisting of one ring with respect to the other ring in a clockwise or counterclockwise manner. These two enantiomeric structures would conformationally interconvert to each other. In the case where two achiral rings of [6]PAM are mechanically bound and doubly-bridged (Schemes 1 and 2b), the relative arrangement of the two rings would be defined, based on the shape-persistency of [6]PAM, and the resulting chirality would be configurationally stable. In the last case where a single larger ring of [12] $\mathrm{PAM}^{19}$ is generated (Schemes 1 and 2c), double-bridging would lead to a specifically-folded structure since such a larger ring would prefer nonplanar conformations rather than a planar conformation. To the best of our knowledge, there has been no previous report on any chiral structure based on [12]PAM, and nothing is known about its chiroptical properties.

Thus, we designed two series (1-5 and 6-8) of chiral molecules in which two rings of [6]PAM are stacked one above the other (1 and 6), two rings of [6]PAM are bound to each other mechanically (3-5 and 8), and a single larger ring of [12]PAM is 


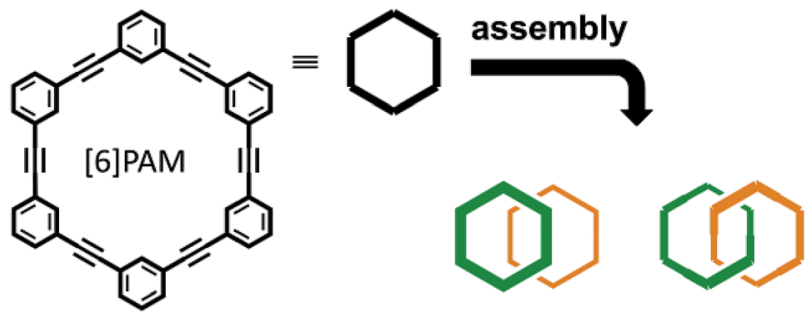

[6]PAM $\times 2$ stacked interlocked
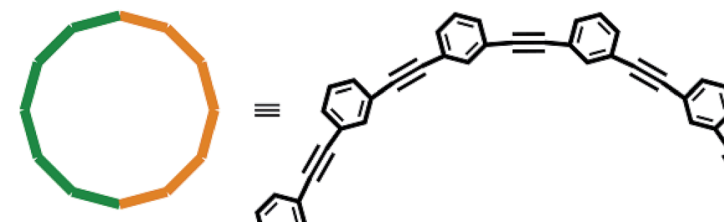

enlarged

[12]PAM $\times 1$

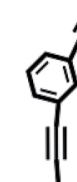

[12]PAM

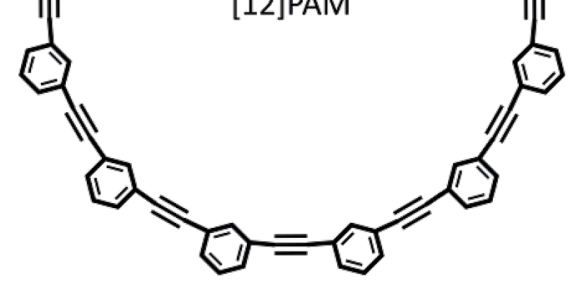

Scheme 1 Generation of multiple forms through the assembly of achiral [6]PAMs.

helically-folded (2 and 7) (Fig. 1 and S1 $\dagger$ ). Double bridging not only assures the generated stereochemistry in $\mathbf{3 - 5}$ and $\mathbf{8}$, it is also the origin of diversification. For descriptive purposes, we numbered six benzene rings starting from either of the two benzene rings that is bridged to another [6]PAM. Doublebridging at the 1- and 3-positions led us to assume three different chiral molecules $(3,4$ and 5$)$. With double-bridging at the 1- and 4-positions, only a single chiral molecule could be designed (8). The type of chirality generated here should be classified as mechanical helical chirality due to the equivalence of the 1- and 3-, or 1- and 4-positions due to arbitrary numbering. Thus, the ring is not oriented to have any priority for the 1-position relative to the 3- or 4-position, which is necessary for topologically-chiral molecules. ${ }^{6,7}$

We should be able to observe the chiroptical properties of dynamic chiral molecules when they interact with an external chiral source, such as in diastereomeric complexation with a chiral guest. Through the supramolecular transmission of external chirality to dynamic chiral structures in a complex, one of two enantiomeric conformations would be preferred over the other. Based on the imbalance between their populations, chiroptical properties would be observable. Terephthalamide was used to serve as both the binding site for capturing a guest and the chirality-transmitting site in bridges. Alternatively, undynamic chiral molecules will show chiroptical properties after enantiomeric separation.

The results of chiral diversification through the assembly of achiral PAMs with a two-fold bridge, molecular structures and chiroptical properties are described below. (a) Dynamic helical chirality generated in helically-stacked two rings

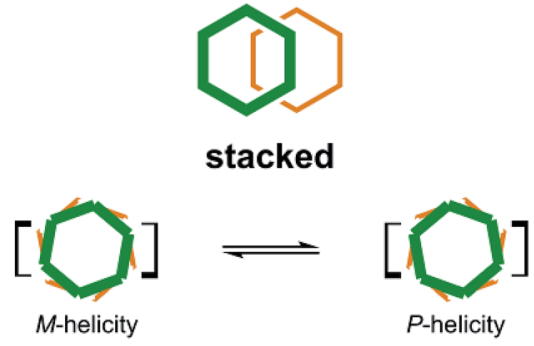

(b) Undynamic helical chirality

due to double-bridging of mechanically-interlocked two rings<smiles>C1C2CC3CC1CC(C2)C3</smiles>

\section{interlocked}

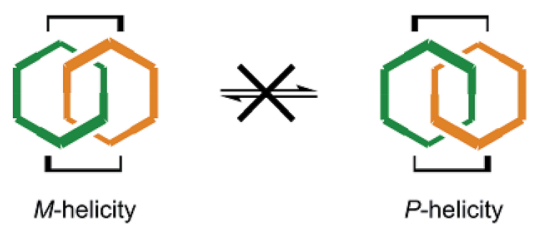

(c) Dynamic helical chirality generated in a helically-folded ring

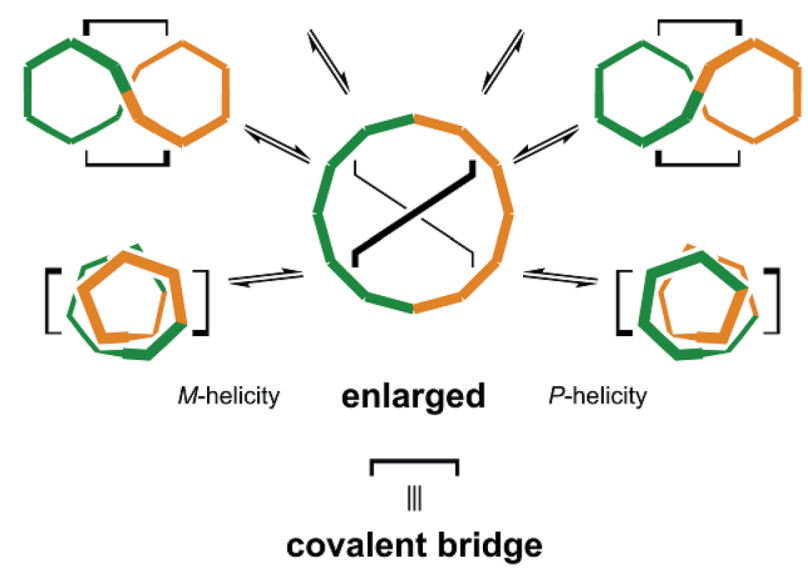

Scheme 2 Dynamic or undynamic helical chirality generated in (a) doubly-bridged two rings of [6]PAM stacked one above the other, (b) doubly-bridged two rings of [6]PAMs mechanically-interlocked to each other, and (c) a doubly-bridged single ring of [12]PAM.

\section{Results and discussion}

\section{Synthesis}

Templated synthesis is one of the most important methods for producing sophisticated molecules. ${ }^{11,20}$ Also, a "covalent template-strategy" would be useful. ${ }^{21}$ By considering the case of an intramolecular two-fold ring-closure reaction, ${ }^{15}$ we assumed that there could be multiple products in which two bonds are formed: a pair of rings and a single enlarged ring (Scheme 3).

For intramolecular two-bond formation (covalent templatestrategy), we designed achiral precursors 9 and 10 (Scheme 3 and Fig. 2). They are composed of two linear [6]phenylacetylene (PA) sequences that are covalently assembled to form 


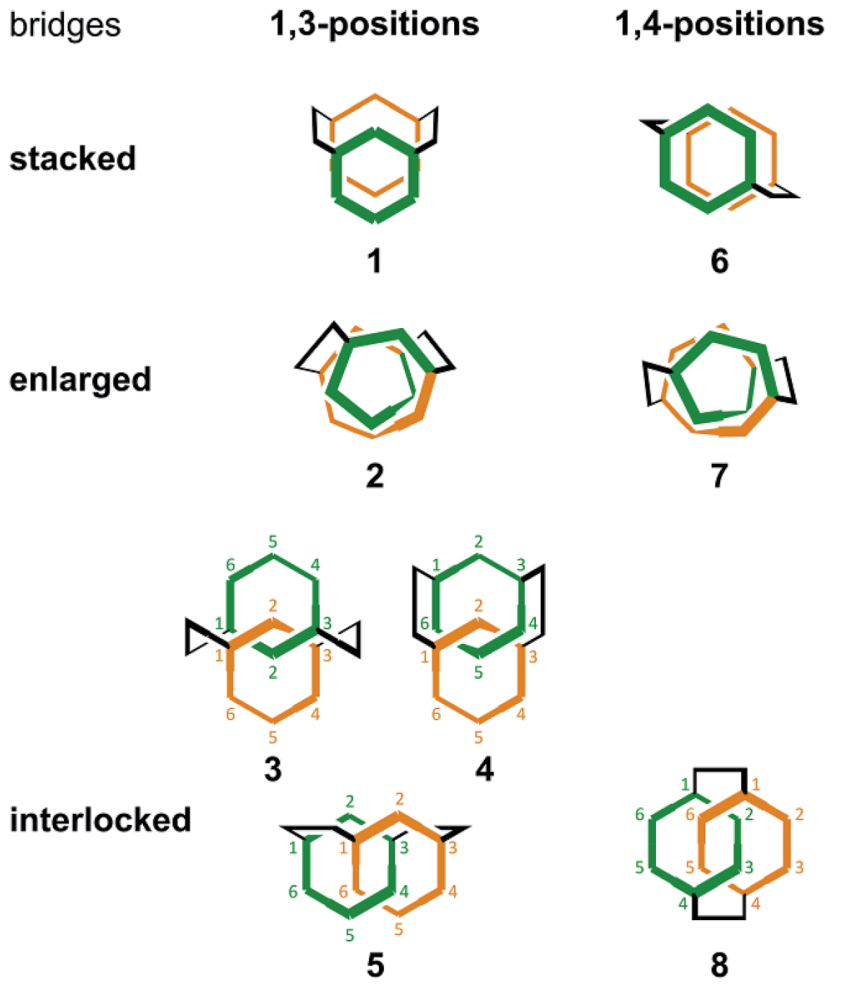

Fig. 1 Schematic representation of 1 and 6 (stacked, [6]PAM $\times 2$ ), 2 and 7 (helically-folded, [12]PAM $\times 1$ ), and 3-5 and 8 (interlocked, [6] PAM $\times 2$ ). Bridges were at the 1- and 3-positions of each PAM for 1-5 and at the 1- and 4-positions for 6-8. The position number is arbitrary. Only one of two enantiomeric conformers/isomers is depicted. Interlocked $( \pm)-5$ have not been synthesized.

a macrocyclic framework. Two-bond formation was implemented by a two-fold Sonogashira coupling reaction of $\alpha$-iodo$\omega$-ethynyl sequences. ${ }^{18 a}$ Based on the difference in the relative direction of the paired sequences, two achiral isomers, a $\left(C_{2 \mathrm{~h}}\right)$ and $\mathbf{b}\left(C_{2 \mathrm{v}}\right)$, were possible for both $\mathbf{9}$ and $\mathbf{1 0}$. We can assume two reaction pathways I and II (Scheme 3 and Fig. 2). One will give two rings of [6]PAM and the other will give a single larger ring of
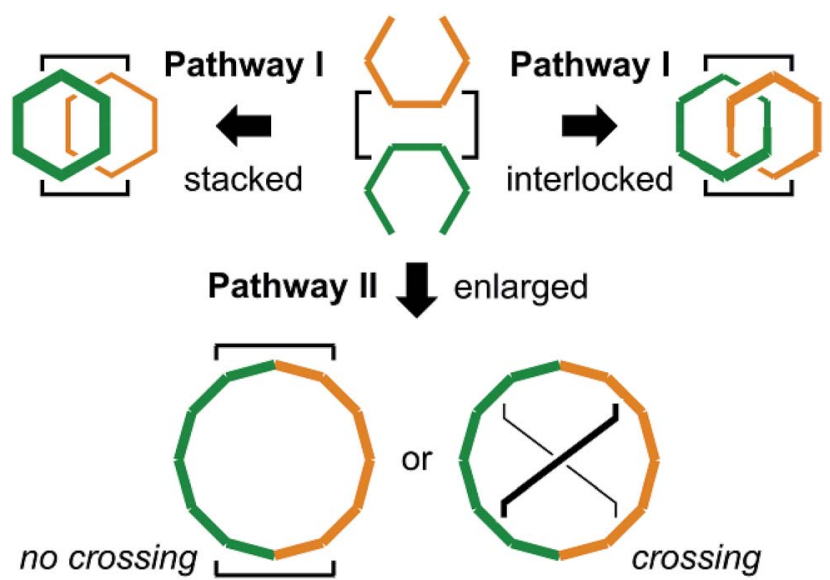

Scheme 3 Synthetic strategy based on intramolecular two-bond formation ("covalent template-strategy").

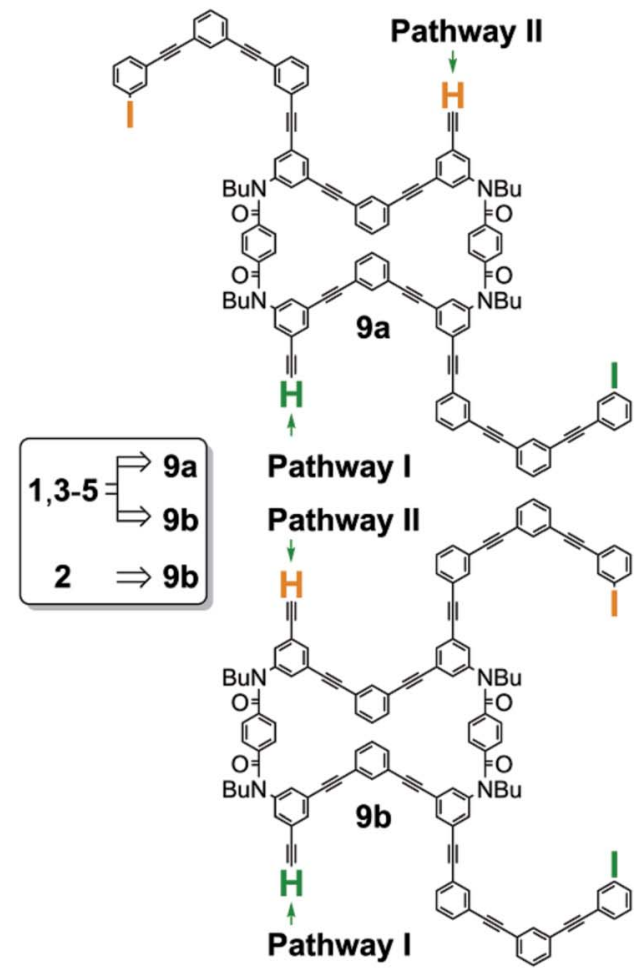

Pathway I (I/H and $\mathrm{I} / \mathrm{H})$ : [6]PAM formation Pathway II (I/H and I/H): [12]PAM formation

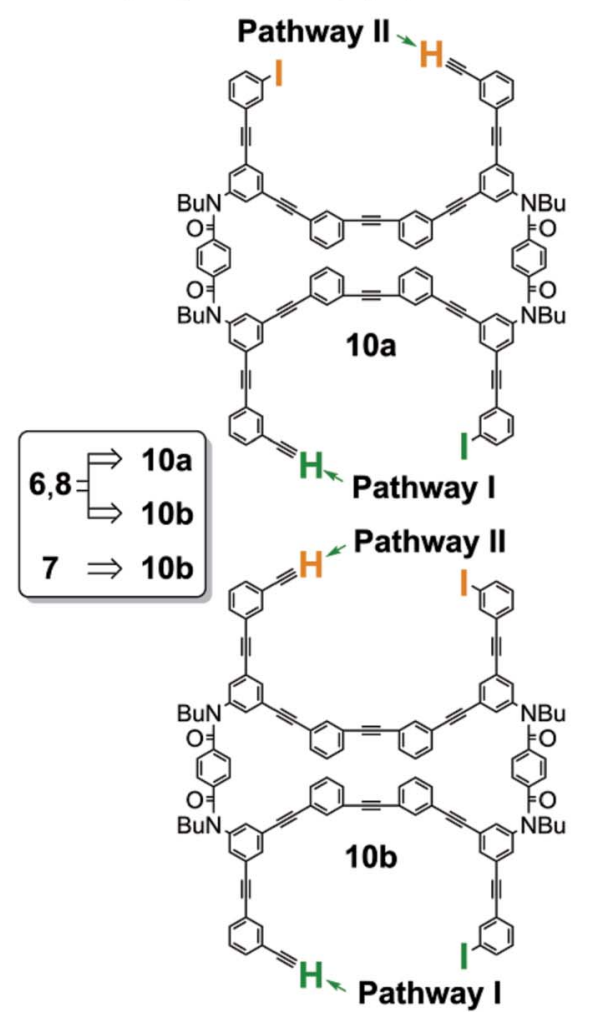

Fig. 2 Chemical structures of ring-closing precursors $9 a / b$ and $10 a / b$.

[12]PAM with or without crossing. These two pathways would be competitive if the conformational flexibility of the linear sequences remained in the macrocyclic framework. Thus, we 
expected at most five helically-chiral molecules (1-5 with a twofold bridge at the 1- and 3-positions) from 9, and three helicallychiral molecules (6-8 with a two-fold bridge at the 1- and 4positions) from 10.

Achiral ring-closing precursors 9a and 9b were separable from each other. ${ }^{22}$ A set of three products (1, 3 and 4) were obtained from 9a (Scheme 4a). All of them were considered to generate via pathway I. This result indicated that pathway II was invalid, which could have led to the generation of a [12]PAM without crossing. Another set of products (2, 3 and 4) were obtained from 9b (Scheme 4a). Compound 5 was not obtained from either $\mathbf{9 a}$ or $\mathbf{9 b}$.

Achiral ring-closing precursors 10a and 10b were inseparable (approx. 1:1 mixture), and they were subjected to the final reaction together. A set of three products $(6,7$ and 8$)$ were obtained (Scheme 4b).

Products 1-4 each exhibited a specific retention time on silica gel, and could be successfully isolated through HPLC separation. Similar separation was applied to 6-8. The ${ }^{1} \mathrm{H}$ NMR spectra of 1-4 and 6-8 showed that they were distinct from each other (Fig. 5, described later). Mass analyses showed that they each had a molecular weight of 1746 . Based on these results, we could confirm that products 1-4 and 6-8 were all isomers with an identical composition $\left(\mathrm{C}_{128} \mathrm{H}_{88} \mathrm{~N}_{4} \mathrm{O}_{4}\right)$. Enantiomeric separation was possible only for $( \pm)-3$ and $( \pm)$-8. Unfortunately, racemates $( \pm)$-4 remained inseparable even with considerable effort. $^{23}$

Model rings of [6]PAM 11 (ref. 16a) and 12 were prepared for comparison of NMR and UV spectra. A model macrocycle $\mathbf{1 3}$ is composed of two halves of a [6]PA sequence that are doublybridged, and was used for monitoring complexation by ${ }^{1} \mathrm{H}$ NMR spectroscopy, since most protons were well-assigned. Chiral ditopic guests $(R, R)-\mathbf{1 4}$ and $(S, S)$-14 were used as an external chiral source. ${ }^{16}$ They could be captured by the formation of hydrogen bonds at terephthalamide bridges (Fig. 3, Schemes S1, S3 and S4†).

\section{Molecular structures}

Conformational searches. We considered whether the isomers 1-8 $(\mathrm{NBu})$ could adopt some chiral structure through conformational searches for models $\mathbf{1}^{\prime}-\mathbf{8}^{\prime}$ (NMe). The lowest energy structures for each isomer are shown in Fig. 4. Other several structures were also found (Fig. S2†). Dynamic interconversion between conformers seems to occur through a)

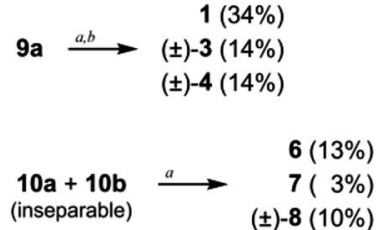

$( \pm)-8(10 \%)$
$2(26 \%)$

9b $\stackrel{a, c}{\longrightarrow}( \pm)-3(13 \%)$

$( \pm)-4(11 \%)$

\section{b)}

Scheme 4 Synthetic results of the intramolecular ring-closure reactions with (a) $9 a$ or $9 b$, or (b) a mixture of $10 a$ and $10 b$. ${ }^{a}$ Pseudo-highdilution conditions: $\mathrm{Pd}\left(\mathrm{PPh}_{3}\right)_{4}, \mathrm{Cul}, \mathrm{Et}_{3} \mathrm{~N}, \mathrm{THF}, 80{ }^{\circ} \mathrm{C} .{ }^{b}$ Folded 2 and

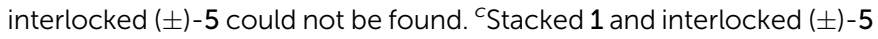
could not be found.

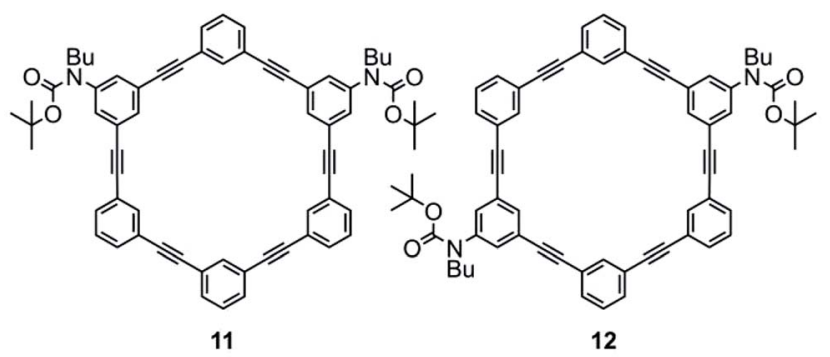

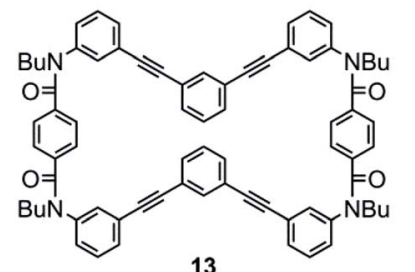

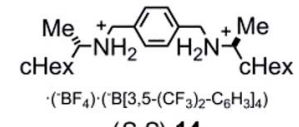

$(S, S)-14$

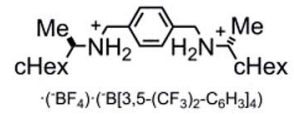

$(R, R)-14$
Fig. 3 Chemical structures of model [6]PAMs 11 (ref. 16a) and 12, a model macrocycle 13 , and chiral guests $(R, R)-14$ and $(S, S)-14{ }^{16}$

dynamic interconversion between local conformations ( $m$-helicity, non-helicity or $p$-helicity) in the bridges (Fig. $\mathrm{S} 1 \dagger$ ).

For models $\mathbf{1}^{\prime}$ and $\mathbf{6}^{\prime}$ with two rings of [6]PAM stacked one above the other, the lowest energy structures were found to be

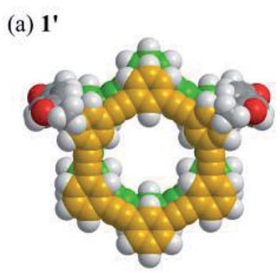

(c) 3'

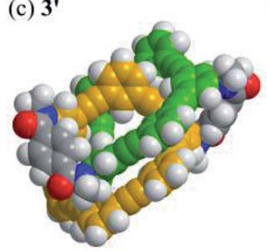

(f) $6^{\prime}$

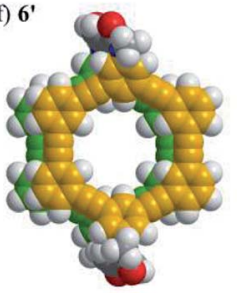

(d) $4^{\prime}$

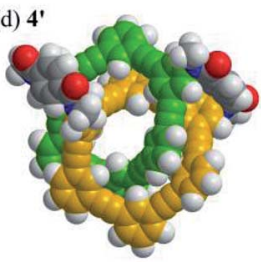

(b) $2^{\prime}$

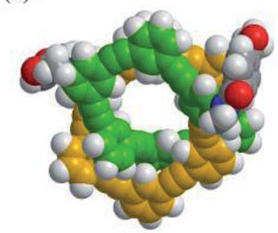

(e) $5^{\prime}$ (g) $7^{\prime}$

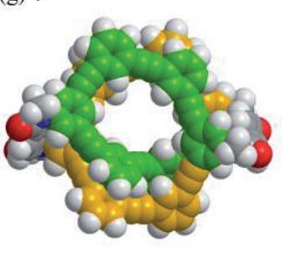

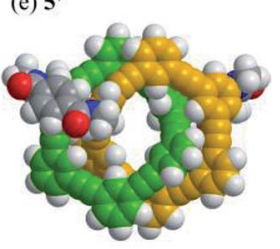

(h) $\mathbf{8}^{\prime}$

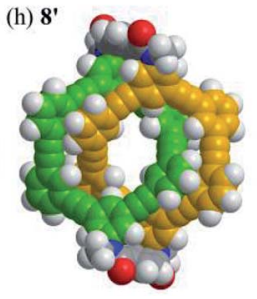

Fig. 4 The lowest energy structures for models $1^{\prime}-8^{\prime}$ (NMe, $\left.\mathrm{C}_{116} \mathrm{H}_{64} \mathrm{~N}_{4} \mathrm{O}_{4}\right)$ : (a) $1^{\prime}\left(+6.5 \mathrm{~kJ} \mathrm{~mol}^{-1}\right)$, (b) $2^{\prime}\left(+30.6 \mathrm{~kJ} \mathrm{~mol}^{-1}\right)$, (c) $3^{\prime}$ $\left(+24.0 \mathrm{~kJ} \mathrm{~mol}^{-1}\right),(\mathrm{d}) 4^{\prime}\left(+5.0 \mathrm{~kJ} \mathrm{~mol}^{-1}\right),(\mathrm{e}) 5^{\prime}\left(+14.6 \mathrm{~kJ} \mathrm{~mol}^{-1}\right),(\mathrm{f}) 6^{\prime}$ $\left(+5.4 \mathrm{~kJ} \mathrm{~mol}^{-1}\right),(\mathrm{g}) 7^{\prime}\left(+23.0 \mathrm{~kJ} \mathrm{~mol}{ }^{-1}\right)$ and (h) $8^{\prime}\left(\mathrm{rel} 0 \mathrm{~kJ} \mathrm{~mol}{ }^{-1}\right.$ ), obtained by conformational searches using MacroModel software (v11.8 OPLS3e, Monte Carlo Multiple Minimum method, non-solvated, 100000 steps). 
achiral (Fig. 4a and f). Alternatively, a helically-chiral structure was found at a higher energy level for both model isomers (Fig. S1† and $\mathrm{S} 2 \mathrm{~B} \dagger$ ). These achiral and helically-chiral structures would be conformationally accessible to each other.

For models $2^{\prime}$ and $7^{\prime}$ with a larger ring of [12]PAM, helicallyfolded structures were found. The global chirality seems to enable the bridges to adopt only one form with a particular sense of local helicity and/or a non-helical form (Fig. S2C †). If so, the inversion of local helicity in the bridge would accompany the inversion of global helicity, similar to $\mathbf{1}^{\prime}$ and $\mathbf{6}^{\prime}$.

For models $3^{\prime}, \mathbf{4}^{\prime}, \mathbf{5}^{\prime}$ and $\mathbf{8}^{\prime}$ with two rings of [6]PAM bound to each other mechanically, chiral structures were definitely found. No rings adopted a planar conformation. While dynamic motion in the bridge would lead to a different structure, the stereochemistry of these molecules should be maintained (Fig. S1 and $\left.\mathrm{S} 2 \mathrm{D}^{\dagger}\right)$.

For model $\mathbf{1 3}^{\prime}$, several structures were found within a very tight range of energy levels (Fig. $\mathrm{S} 2 \mathrm{~A} \dagger$ ). It seems that this would be desirable for a synthetic precursor to generate multiple structures in the current system. In fact, similar conformations were found in the structures of $\mathbf{1}^{\prime}$ and $\mathbf{2}^{\prime}$.

NMR spectroscopy. The ${ }^{1} \mathrm{H}$ NMR spectra, measured at room temperature, of 1-4 and 6-8 showed that they were distinct from each other (Fig. 5 and S3 $\dagger$ ). The ${ }^{13} \mathrm{C}$ NMR spectra are also shown in the ESI (Fig. S4†). Complete assignments were difficult due to broadening and/or overlapping of several proton signals. Some information on conformational flexibility was given by spectra measured at various temperatures (223-323 K) (Fig. S5†). For all of the isomers, the existence of anisochronicity for the geminal methylene protons closest to the nitrogen atom indicated that they were located near some chiral environment.

Integral values for inner protons $\left(\mathrm{H}^{\mathrm{A}}, \mathrm{H}^{\mathrm{B}}\right.$ and $\left.\mathrm{H}^{\mathrm{C}}\right)$ of $\mathbf{1}$ showed that the two rings of [6]PAM were equivalent. At lower temperatures, several species in different populations were observed. They were averaged with a rise in temperature through dynamic conformational interconversions. The two rings of [6]PAM in 6 were also equivalent. The different chemical shifts for $\mathrm{H}^{\mathrm{A}}$ and $\mathrm{H}^{\mathrm{A}^{\prime}}$ show a situation where one ring is stacked away from right above the other.

Although broadened resonances for 2 provided less information on the structure, the chemical shift values for most protons were maintained to some extent over the entire range of temperatures. This suggested the existence of a dominant conformation in solution. This suggestion also applied to 7 .

At each temperature examined, we observed only one singlet peak for phenylene protons $\left(\mathrm{H}^{\mathrm{T}}\right)$ of terephthalamide in $\mathbf{3}$ and $\mathbf{8}$, while the corresponding protons in $\mathbf{4}$ were split to be nonequivalent $\left(\mathrm{H}^{\mathrm{T}}\right.$ and $\left.\mathrm{H}^{\mathrm{T}^{\prime}}\right)$ below $283 \mathrm{~K}$. This was used to determine 3 or 4 .

Possible explanations for the identification of 1-4 were discussed based on not only less informative results of NMR spectroscopy, but also several preliminary synthetic results with the use of model intermediates with a single ring of [6]PAM (Scheme S2) in the ESI_1. $\dagger$

For model macrocycle 13, we observed a single set of averaged resonances over the entire range of temperatures. Most protons were well-assigned (Fig. S5h and S6a†). The chemical
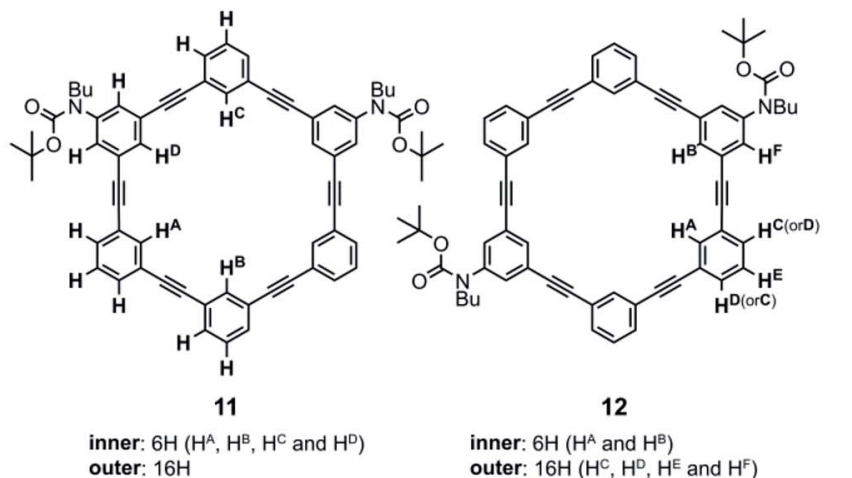

12

inner: $6 \mathrm{H}\left(\mathrm{H}^{A}, \mathrm{H}^{B}, \mathrm{H}^{C}\right.$ and $\left.\mathrm{H}^{D}\right) \quad$ inner: $6 \mathrm{H}\left(\mathrm{H}^{A}\right.$ and $\left.\mathrm{H}^{B}\right)$
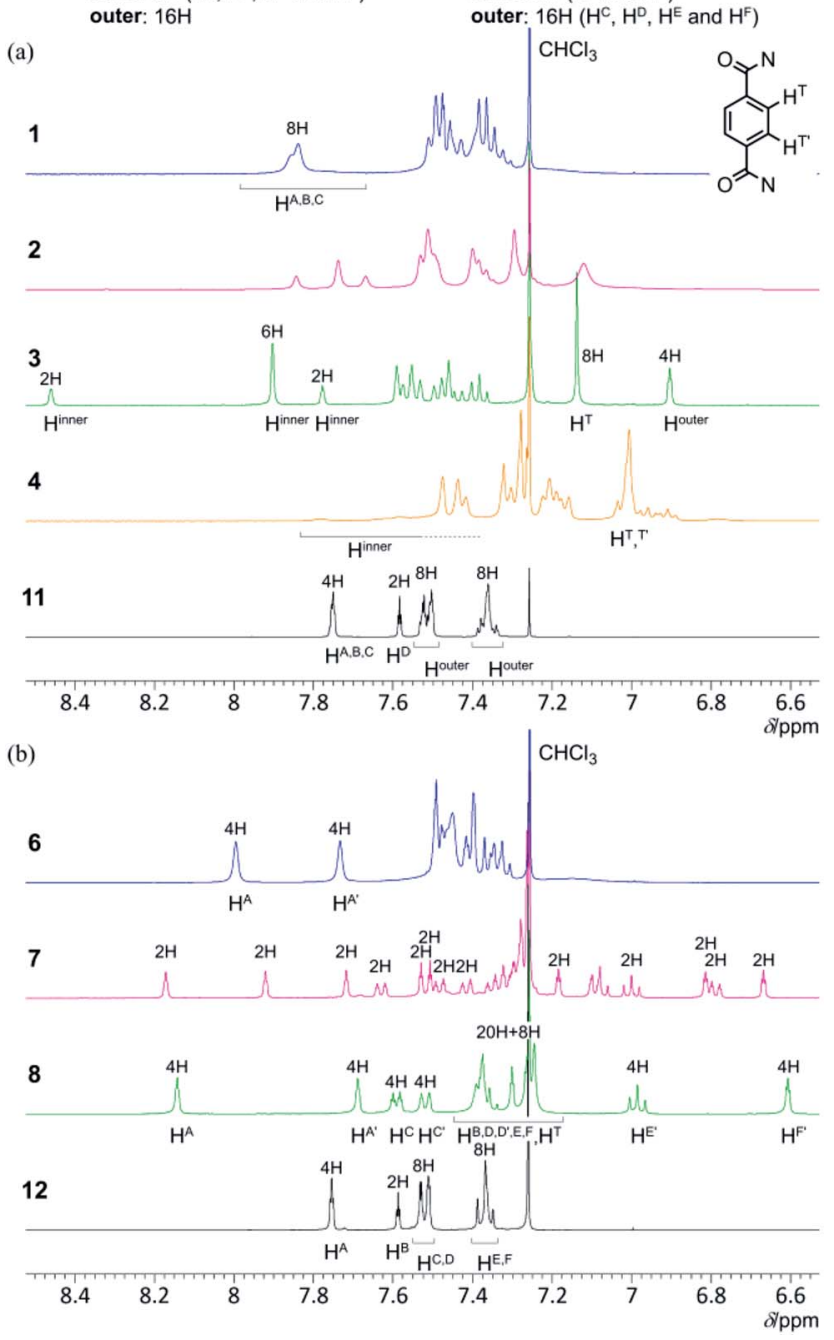

Fig. 5 Partial ${ }^{1} \mathrm{H}$ NMR spectra (400 MHz) of (a) 1-4 and 11, and (b) 6-8 and 12 , measured in chloroform- $d$ at room temperature.

shift of averaged resonances for some protons changed with temperature. This was attributed to dynamic interconversion among several conformations with different structures.

UV spectroscopy. For all isomers 1-4 and 6-8, we found characteristic absorptions at $305-308 \mathrm{~nm}$ and at 287 or $288 \mathrm{~nm}$ (Fig. 6). The spectra of the models 11 and 12 showed an identical set of these characteristic absorptions. Also, model macrocycle 13 composed of two halves of a [6]PA sequence gave similar results in terms of absorption wavelength. 


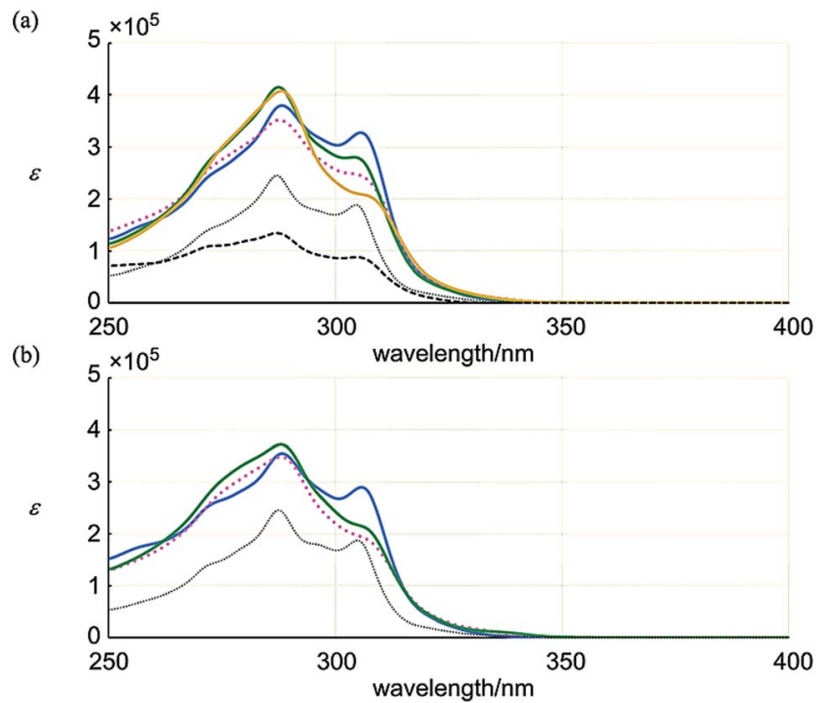

Fig. 6 UV spectra of (a) 1 (blue solid line), 2 (pink dotted line), 3 (green solid line), 4 (yellow solid line), 11 (black thin dotted line) and 13 (black thick dashed line), and (b) 6 (blue solid line), 7 (pink dotted line), 8 (green solid line) and 12 (black thin dotted line). All spectra were measured in dichloromethane at room temperature.

Next, we considered the absorption intensity based on the ratio of molar extinction coefficients $\varepsilon_{1}$ and $\varepsilon_{2}$ (Table 1 ). The value for $\mathbf{6}$ was close to that of $\mathbf{1 2}$ with a single ring of [6]PAM. This similarity indicated that the two rings of [6]PAM in 6 behaved electronically-independently to maintain the original electronic property in a stacked structure of 6 . The close values for $\mathbf{7}$ and $\mathbf{8}$, which were distinct from that of $\mathbf{6}$, suggests that they share some common physical features.

In the series 1-4, none of the structures had a value close to that of $\mathbf{1 1}$. These structures, especially $\mathbf{4}$, might undergo some physical perturbation that deviates from the single ring of [6] PAM itself.

\section{Chiroptical properties}

Model study. First, we demonstrate the complexation of model 13 with a chiral ditopic guest $(R, R)-\mathbf{1 4}$ by ${ }^{1} \mathrm{H}$ NMR spectroscopy (Fig. 7a). When we mixed them in $3: 97(\mathrm{v} / \mathrm{v})$

Table 1 Wavelengths $\left(\lambda_{1}\right.$ and $\left.\lambda_{2}, \lambda_{1}>\lambda_{2}\right)$ of absorption maximum, molar extinction coefficients $\left(\varepsilon_{1}\right.$ and $\left.\varepsilon_{2}\right)$ and the ratio of $\varepsilon_{1} / \varepsilon_{2}$, measured in dichloromethane at room temperature

\begin{tabular}{llllll}
\hline & $\lambda_{\text {max }} / \mathrm{nm}$ & $\varepsilon_{1} / 10^{5}$ & $\lambda_{\max } / \mathrm{nm}$ & $\varepsilon_{2} / 10^{5}$ & $\varepsilon_{1} / \varepsilon_{2}$ \\
\hline $\mathbf{1}$ & 306 & 3.28 & 288 & 3.81 & 0.86 \\
$\mathbf{2}$ & 306 & 2.44 & 288 & 3.52 & 0.69 \\
$\mathbf{3}$ & 304 & 2.81 & 287 & 4.15 & 0.68 \\
$\mathbf{4}$ & 309 & 1.97 & 288 & 4.08 & 0.48 \\
$\mathbf{1 1}$ & 305 & 1.88 & 287 & 2.45 & 0.77 \\
$\mathbf{1 3}$ & 305 & 0.879 & 287 & 1.35 & 0.65 \\
$\mathbf{6}$ & 306 & 2.89 & 288 & 3.54 & 0.82 \\
$\mathbf{7}$ & 308 & 1.83 & 288 & 3.48 & 0.53 \\
$\mathbf{8}$ & 308 & 2.02 & 288 & 3.72 & 0.54 \\
$\mathbf{1 2}$ & 305 & 1.87 & 287 & 2.45 & 0.77
\end{tabular}

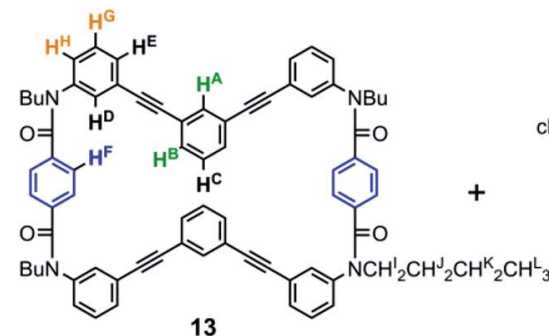

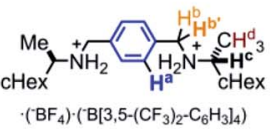

$(R, R)-14$

13

(a)
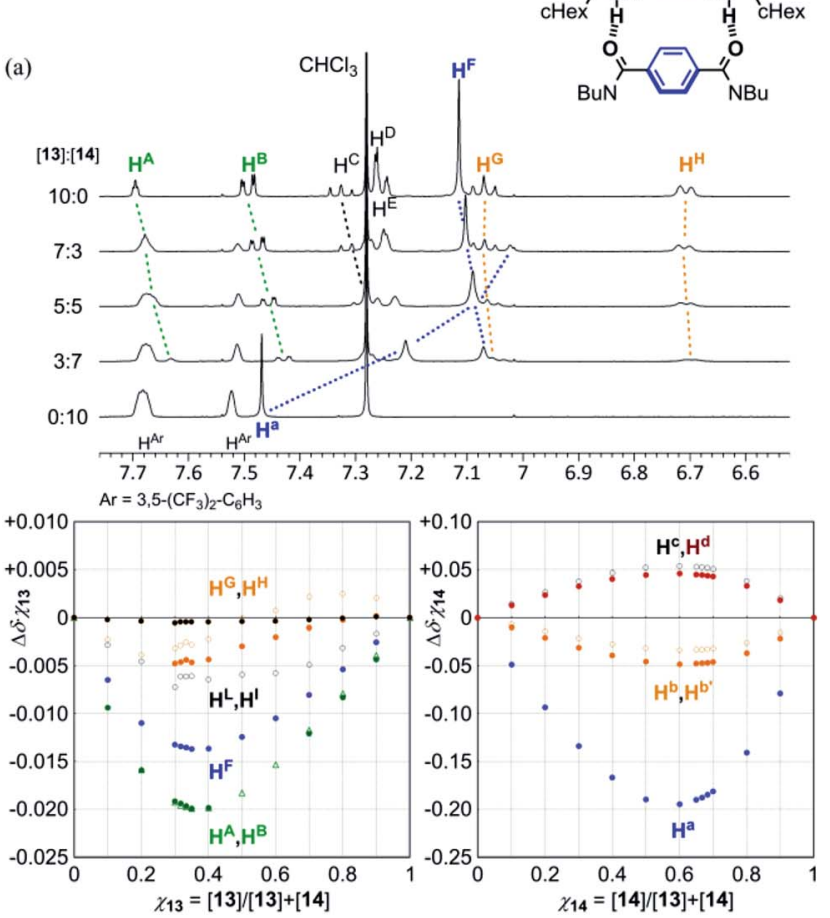

(b)

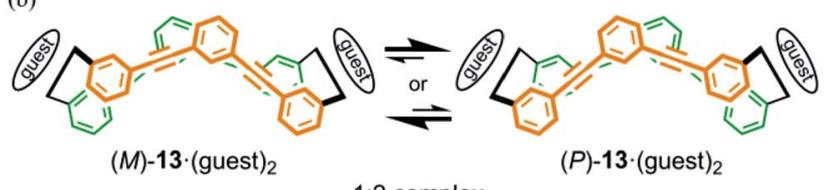

$1: 2$ complex

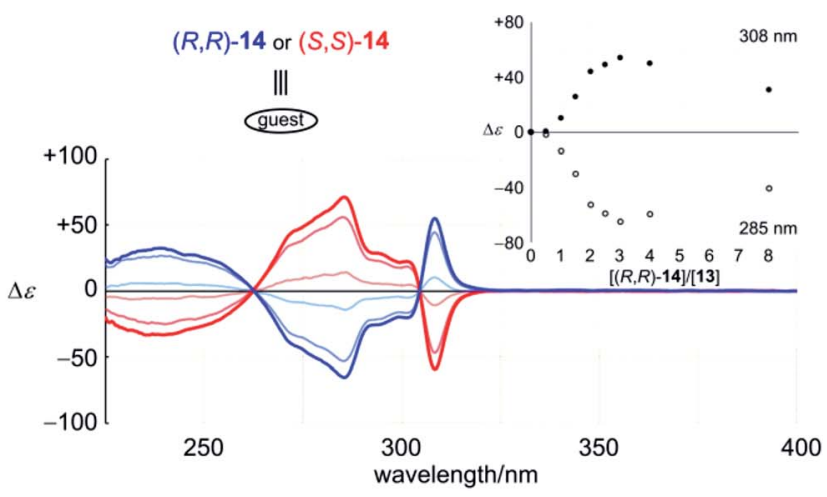

Fig. 7 Complexation of model macrocycle 13 with chiral guests $(R, R)$ 14 or $(S, S)-14$ : (a) partial ${ }^{1} \mathrm{H}$ NMR spectra of 13 in the presence of $(R, R)$ 14 [[13] : [14] $=0: 10$ (14 only), 3: 7, 5:5, $7: 3$ and $10: 0$ (13 only)], and Job plots $([13]+[(R, R)-14]=2 \mathrm{mM}$, measured in $3: 97(\mathrm{v} / \mathrm{v})$ acetonitrile- $d_{3} /$ chloroform- $d$ at $\left.303 \mathrm{~K}\right)$; (b) CD spectra of $13(1.3 \times$ $\left.10^{-4} \mathrm{M}\right)$ in the presence of $(R, R)-14$ (blue lines: 1,2 and 3 equiv.) or $(S, S)-14$ (red lines), measured in dichloromethane at $293 \mathrm{~K}$ [inset: plots of induced molar CD versus equivalents of guest added]. 
acetonitrile- $d_{3} /$ chloroform- $d$, upfield shifts were induced for both the central phenylene protons $\left(\mathrm{H}^{\mathrm{F}}\right)$ in the bridge of $\mathbf{1 3}$ and the central phenylene protons $\left(\mathrm{H}^{\mathrm{a}}\right)$ in 14. This result showed that the ditopic guest was captured at the two amide groups in the bridge. For other protons far from the binding site, several complexation-induced shifts were observed. This result showed a change in populations of several conformations at equilibrium before and after complexation. Based on these complexation-induced changes in the chemical shift, Job plots were created to confirm that the stoichiometry of a complex was $1: 2$. Through a titration experiment, the binding constants were estimated $\left(K_{1}=5.8 \times 10^{2} \mathrm{M}^{-1}, K_{2}=1.5 \times 10^{3} \mathrm{M}^{-1}\right)$ (Fig. S6a $\dagger$ ). ${ }^{24}$ We considered that the sigmoidal curve was caused by a change in the conformation of 13 upon complexation.

Next, we monitored $1: 2$ complexation, at a lower concentration in dichloromethane, by UV and CD spectroscopy. When the guest $(R, R)$-14 was added to a solution of 13, we observed changes in the appearance of the UV spectrum of 13 (Fig. S6b $\dagger$ ). This result showed that dynamic equilibrium among conformations was perturbed upon complexation, as shown by changes in the chemical shift in ${ }^{1} \mathrm{H}$ NMR spectroscopy. In the CD spectrum of $\mathbf{1 3}$ (Fig. 7b), Cotton effects were induced in the absorption region of 13. During addition of the guest at up to 3 equivalents, while the appearance of the spectrum was maintained, the intensity increased with an increase in the concentration of the guest. If we consider that Cotton effects originated only from chiral species, any intermediary complex, e.g., a $1: 1$ complex, was negligible due to the positive allosterism. Mirror images were obtained by addition of the antipodal guest $(S, S)$ 14. This result showed that model macrocycle 13 could adopt dynamic chiral conformations $[(M)-\mathbf{1 3}$ and $(P)-\mathbf{1 3}]$. When it formed diastereomeric complexes with a particular chiral guest $\left[(M)-\mathbf{1 3} \cdot(R, R)-\mathbf{1 4}_{2}\right.$ and $\left.(P)-\mathbf{1 3} \cdot(R, R)-\mathbf{1 4}_{2}\right]$, one complex with a particular chiral sense was preferred over the other. There is no chiral-sense preference in $\mathbf{1 3}$ itself. In an earlier stage of the addition of the guest, Cotton effects were sigmoidally increased (Fig. 7b, inset), as in the NMR titration experiment. The induced Cotton effects decreased to some extent in the presence of abundant equivalents. This decrease in intensity was attributed to the emergence of higher-ordered complexes [1: $n(n>2)]$, in which some ditopic guest was forced to be bound in a monotopic manner, and was not enabled to transfer its chirality. At room temperature or above, ${ }^{25}$ induced Cotton effects were attenuated with an increase in temperature (Fig. S6c $\dagger$ ), as often seen in most systems based on dynamic equilibrium.

Dynamic chiral molecules 1 and 6 with two rings of [6]PAM stacked one above the other. We monitored the complexation of $\mathbf{1}$ or 6 with chiral ditopic guests $(R, R)-\mathbf{1 4}$ or $(S, S)-\mathbf{1 4}$ in dichloromethane by UV and CD spectroscopy. When a guest was added to a solution of $\mathbf{1}$, unlike in the above model case, there was only a slight change in the UV spectrum of $\mathbf{1}$ (Fig. S7a†). In the CD spectrum, the spectral appearance gradually changed with the concentration of the added guest (Fig. 8a). This result indicated that the initially-formed chiral complex was different from the ultimately-formed chiral complex. VT-CD measurements at 263-313 K showed a great change in Cotton effects
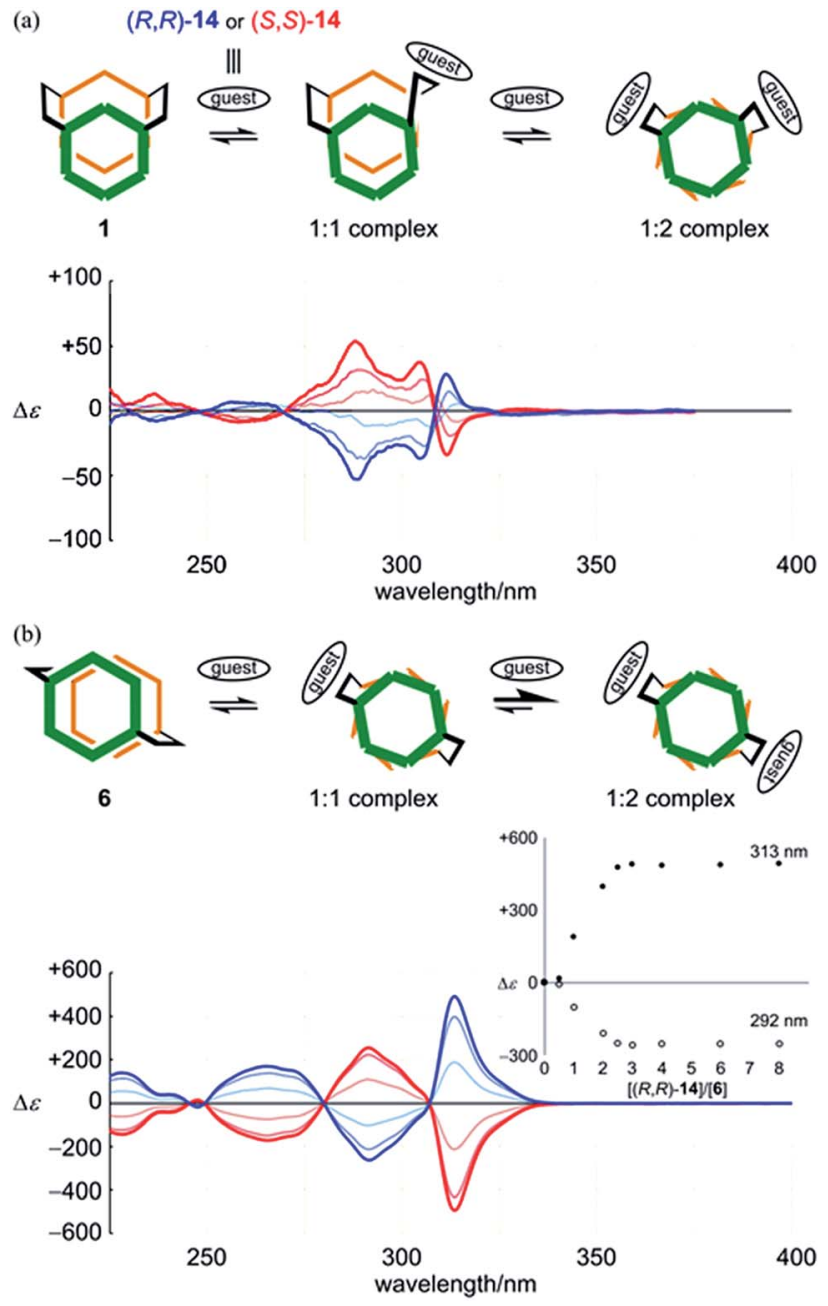

Fig. 8 CD spectra of (a) $1\left(4.4 \times 10^{-5} M\right)$ and (b) $6\left(4.8 \times 10^{-5} \mathrm{M}\right)$ in the presence of $(R, R)-14$ (blue lines: 1,2 and 4 equiv. for $1,1,2$ and 3 equiv. for 6) or (S,S)-14 (red lines), measured in dichloromethane at $293 \mathrm{~K}$ [inset: plots of induced molar CD versus equivalents of the guest added].

with several isochoric points (Fig. S7c $\dagger$ ), indicating the presence of an equilibrium between two different chiral species, as well as diastereomeric forms for each chiral species. Consequently, compositive Cotton effects seemed to emerge during the addition of a guest at room temperature.

Alternatively, in the case of $\mathbf{6}$, the addition of a guest led to a continuous change in the UV spectrum of 6 (Fig. S7b $\dagger$ ), and Cotton effects were induced in the absorption region of 6 while the appearance of the CD spectrum was maintained (Fig. 8b). Based on these results, along with those in the ${ }^{1} \mathrm{H}$ NMR spectrum, we considered that there was a change in conformation of 6 from an achiral conformation in the absence of a guest, and thus it could adopt chiral conformations in a complexed state. CD titration curves were obviously sigmoidal (Fig. 8b, inset). The intensity of induced Cotton effects was noteworthy and reminiscent of helical columnar assemblies, ${ }^{\boldsymbol{9}, \boldsymbol{d}}$ even though there existed only two rings stacked helically. VT-CD measurements showed that induced Cotton effects were attenuated or enhanced with an increase or decrease in temperature, while 
the appearance of the spectrum was maintained (Fig. S7d $\dagger$ ). This was the result of dynamic interconversion between two diastereomeric complexes with $(M)$ - or $(P)$-helicity. For both 1 and 6, an antipodal guest led to the induction of mirror-imaged Cotton effects. Thus, the dynamic chirality of $\mathbf{1}$ and $\mathbf{6}$ was elucidated.

Dynamic chiral molecules 2 and 7 with a single larger ring of [12]PAM. As with 1 or 6 , we monitored the complexation of 2 or 7 by UV and CD spectroscopy. Upon the addition of a guest to a solution of 2 , there was a large change in the UV spectrum of 2 (Fig. S8a†). The decrease in absorption at $306 \mathrm{~nm}$ was greater than the decrease at $288 \mathrm{~nm}$. As a consequence, the ratio $A_{306} /$ $A_{288}$ changed from 0.69 to 0.59 . This change seemed to be similar to that induced for some phenylene-ethynylene oligomers upon folding. ${ }^{26}$ In the CD spectrum of 2 , the shape of induced Cotton effects was maintained with an increase in intensity (Fig. 9a). Based on this observation, since the intensity

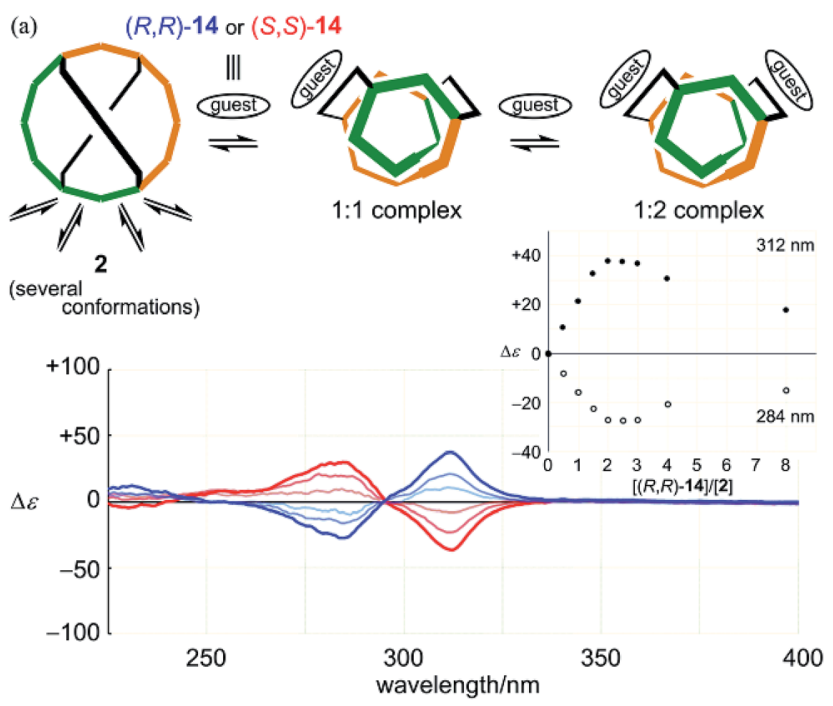

(b)
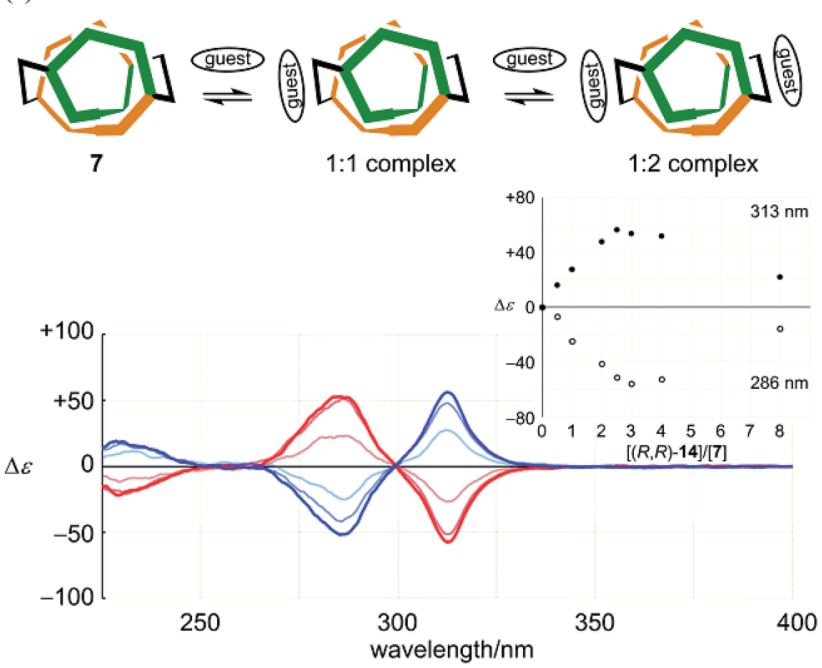

Fig. 9 CD spectra of (a) $2\left(4.8 \times 10^{-5} \mathrm{M}\right)$ and (b) $7\left(4.7 \times 10^{-5} \mathrm{M}\right)$ in the presence of $(R, R)-14$ (blue lines: 0.5, 1 and 2 equiv. for 2, 1, 2 and 2.5 equiv. for 7 ) or $(S, S)-14$ (red lines), measured in dichloromethane at $293 \mathrm{~K}$ [inset: plots of induced molar CD versus equivalents of the guest added]. of induced Cotton effects changed monotonically (Fig. 9a, inset), we could explain the complexation as follows: there was little difference in conformation between the initially-formed chiral complex and the ultimately-formed chiral complex. The induced Cotton effects were similar to those for a foldamer of a [12]PA sequence. ${ }^{26}$ The similarity in the shape of Cotton effects could support the notion that there existed a helical conformation in [12]PAM of 2, at least in a complexed state.

Alternatively, we found no change in absorption upon the addition of a guest to a solution of 7 (Fig. S8b $\dagger$ ). Induced Cotton effects resembled those for a complex of 2 (Fig. 9). Based on these results, we considered that there was no change in the conformation of 7 upon complexation, and that a helical conformation was adopted predominantly regardless of whether the guest was present or not. The guest simply led to a helical-sense preference in a complexed state. Mirrored images were given by the addition of an antipodal guest. Thus, we concluded that helically-chiral conformations existed in a larger ring of [12]PAM, and they were dynamically interconvertible.

Configurationally-stable chiral molecules $( \pm)-3$ and $( \pm)-8$ with two rings of [6]PAM bound to each other mechanically. Through successful enantiomeric separation, we obtained the CD spectra for each isolated enantiomer (Fig. 10). Based on not only the remarkable intensity of Cotton effects but also the specific optical rotation, chiroptical properties were greater for 8 than for $3\left(3:[\alpha]_{D}=+591\right.$ for the first fraction and $[\alpha]_{D}=-573$ for the second fraction; 8: $[\alpha]_{\mathrm{D}}=+1062$ for the first fraction and $[\alpha]_{\mathrm{D}}=-1067$ for the second fraction). Due to the mechanical linkage and double-bridging, racemization was no longer allowed for either $\mathbf{3}$ or $\mathbf{8}$. In the VT-CD spectra of $\mathbf{3}$ and $\mathbf{8}$, we observed a small change in the shape of Cotton effects (Fig. S9†). This was explained by dynamic interconversion

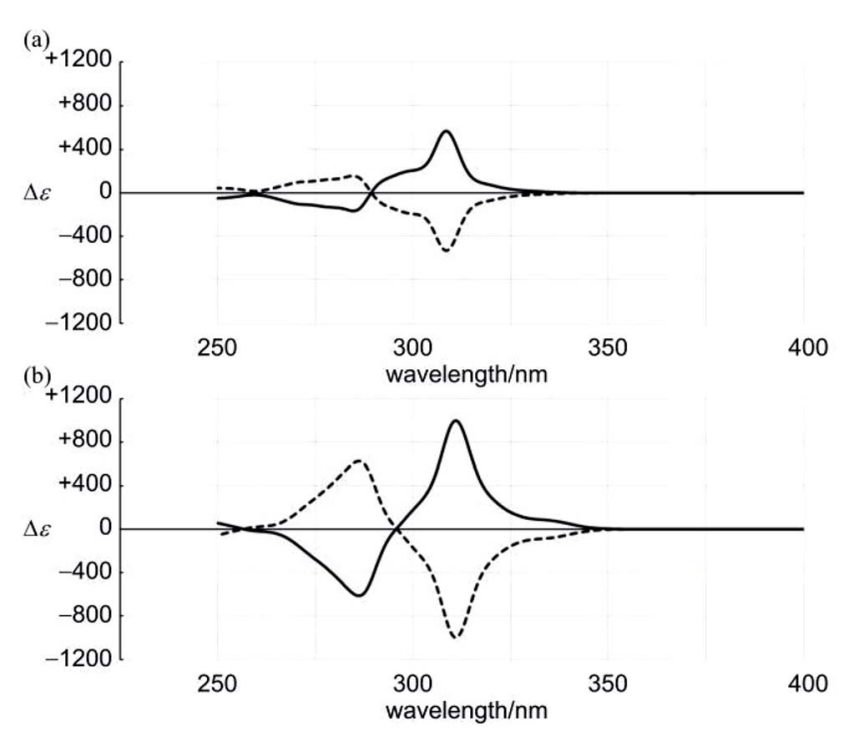

Fig. 10 CD spectra of (a) (+)-3 (solid line, first fraction) and (-)-3 (dashed line, second fraction), and (b) (+)-8 (solid line, first fraction) and (-)-8 (dashed line, second fraction), measured in dichloromethane at $293 \mathrm{~K}$. 
between local conformations in the bridge, which can lead to a conformationally-different structure while maintaining the global stereochemistry.

\section{Conclusions}

Based on the assembly of achiral cyclic components, multiple forms were generated: two rings of [6]PAM or a single larger ring of [12]PAM. In a molecule, these achiral pieces were connected by a two-fold covalent bridge to exert chirality. Based on a difference in the bridging positions (1- and 3-, or 1- and 4positions) on PAMs, two series of chiral molecules were demonstrated (1-5 and 6-8). The bridging position itself contributed to the diversification of chiral molecules, as shown by 3, 4 and 5. As always, it is important to seek to obtain the target molecule selectively. Here, we have considered competitive reactions in the final step of synthesis for the generation of multiple products. Thus, we obtained seven chiral isomers with the same molecular weight. A methodology for obtaining such a series of chiral molecules would be useful for the consideration of chiroptical properties based on definite molecular structures.

Dynamic chirality was demonstrated by two helically-stacked rings of [6]PAM (1 and 6). Especially in 6, the intensity of induced Cotton effects was strikingly great, even with only twomolecule stacking, which was comparable to that of helical columnar assemblies of [6]PAMs. Through a successful enantiomeric separation for two interlocked rings of [6]PAM (3 and 8), we observed remarkable Cotton effects and specific optical rotations. Different values of $[\alpha]_{\mathrm{D}}$ were obtained for $\mathbf{3}$ and $\mathbf{8}$, which had an identical composition. Although there has been no previous report of a chiral structure based on [12]PAM, we observed unique Cotton effects for helically-folded forms in [12] PAM (2 and 7). The enantiomeric conformations of [12]PAM were dynamically interconvertible to each other.

\section{Conflicts of interest}

There are no conflicts to declare.

\section{Notes and references}

1 B. Testa, Helv. Chim. Acta, 2013, 96, 351.

2 (a) J. Wencel-Delord, A. Panossian, F. R. Leroux and F. Colobert, Chem. Soc. Rev., 2015, 44, 3418; (b) J. Yea and S. Ma, Org. Chem. Front., 2014, 1, 1210.

3 (a) T. Kakuta, T. Yamagishi and T. Ogoshi, Chem. Commun., 2017, 53, 5250; (b) M. Nakazaki, K. Yamamoto, S. Tanaka and H. Kametani, J. Org. Chem., 1977, 42, 287; (c) M. Shibahara, M. Watanabe, T. Iwanaga, T. Matsumoto, K. Ideta and T. Shinmyozu, J. Org. Chem., 2008, 73, 4433.

4 (a) J. OuYang and J. Crassous, Coord. Chem. Rev., 2018, 376, 533; (b) K. Kato, Y. Segawa and K. Itami, Synlett, 2019, 30, 370; (c) M. Rickhaus, M. Mayor and M. Juríček, Chem. Soc. Rev., 2016, 45, 1542; (d) J. Bosson, J. Gouin and J. Lacour, Chem. Soc. Rev., 2014, 43, 2824; (e) Y. Shen and C.-F. Chen, Chem. Rev., 2012, 112, 1463; (f) S. Han, A. D. Bond,
R. L. Disch, D. Holmes, J. M. Schulman, S. J. Teat, K. P. C. Vollhardt and G. D. Whitener, Angew. Chem., Int. Ed., 2002, 41, 3223.

5 (a) E. M. G. Jamieson, F. Modicom and S. M. Goldup, Chem. Soc. Rev., 2018, 47, 5266; (b) N. H. Evans, Chem.-Eur. J., 2018, 24, 3101.

6 (a) R. Schmieder, G. Hübner, C. Seel and F. Vögtle, Angew. Chem., Int. Ed., 1999, 38, 3528; (b) C. Reuter, W. Wienand, C. Schmuck and F. Vögtle, Chem.-Eur. J., 2001, 7, 1728; (c) N. Kameta, K. Hiratani and Y. Nagawa, Chem. Commun., 2004, 466; (d) L. D. Movsisyan, M. Franz, F. Hampel, A. L. Thompson, R. R. Tykwinski and H. L. Anderson, J. Am. Chem. Soc., 2016, 138, 1366.

7 (a) Y. Kaida, Y. Okamoto, J.-C. Chambron, D. K. Mitchell and J. P. Sauvage, Tetrahedron Lett., 1993, 34, 1019; (b) C. Yamamoto, Y. Okamoto, T. Schmidt, R. Jäger and F. Vögtle, J. Am. Chem. Soc., 1997, 119, 10547; (c) E. Alcalde, L. Pérez-García, S. Ramos, J. F. Stoddart, A. J. P. White and D. J. Williams, Chem.-Eur. J., 2007, 13, 3964.

8 (a) F. B. L. Cougnon, K. Caprice, M. Pupier, A. Bauzá and A. Frontera, J. Am. Chem. Soc., 2018, 140, 12442; (b) S. D. P. Fielden, D. A. Leigh and S. L. Woltering, Angew. Chem., Int. Ed., 2017, 56, 11166; (c) J. Guo, P. C. Mayers, G. A. Breault and C. A. Hunter, Nat. Chem., 2010, 2, 218; (d) M. Feigel, R. Ladberg, S. Engels, R. Herbst-Irmer and R. Fröhlich, Angew. Chem., Int. Ed., 2006, 45, 5698; (e) O. Lukin and F. Vögtle, Angew. Chem., Int. Ed., 2005, 44, 1456; $(f)$ G. Rapenne, C. Dietrich-Buchecker and J.-P. Sauvage, J. Am. Chem. Soc., 1996, 118, 10932.

9 (a) H. Yamagishi, T. Fukino, D. Hashizume, T. Mori, Y. Inoue, T. Hikima, M. Takata and T. Aida, J. Am. Chem. Soc., 2015, 137, 7628; (b) A. Pop, M. O. Vysotsky, M. Saadioui and V. Böhmer, Chem. Commun., 2003, 1124; (c) X. Zhou, G. Liu, K. Yamato, Y. Shen, R. Cheng, X. Wei, W. Bai, Y. Gao, H. Li, Y. Liu, F. Liu, D. M. Czajkowsky, J. Wang, M. J. Dabney, Z. Cai, J. Hu, F. V. Bright, L. He, X. C. Zeng, Z. Shao and B. Gong, Nat. Commun., 2012, 3, 949; (d) Y. Zhong, Y. Yang, Y. Shen, W. Xu, Q. Wang, A. L. Connor, X. Zhou, L. He, X. C. Zeng, Z. Shao, Z. Lu and B. Gong, J. Am. Chem. Soc., 2017, 139, 15950.

10 T. Prakasam, M. Lusi, E. Nauha, J.-C. Olsen, M. Sy, C. PlatasIglesias, L. J. Charbonnière and A. Trabolsi, Chem. Commun., 2015, 51, 5840.

11 (a) P. R. Ashton, A. S. Reder, N. Spencer and J. F. Stoddart, J. Am. Chem. Soc., 1993, 115, 5286; (b) A. Theil, C. Mauve, M.-T. Adeline, A. Marinetti and J.-P. Sauvage, Angew. Chem., Int. Ed., 2006, 45, 2104; (c) Y. Okada, Z. Miao, M. Akiba and J. Nishimura, Tetrahedron Lett., 2006, 47, 2699; (d) Y. Nakatani, Y. Furusho and E. Yashima, Angew. Chem., Int. Ed., 2010, 49, 5463; (e) R. Mitra, M. Thiele, F. Octa-Smolin, M. C. Letzel and J. Niemeyer, Chem. Commun., 2016, 52, 5977.

12 (a) H.-R. Tseng, S. A. Vignon, P. C. Celestre, J. F. Stoddart, A. J. P. White and D. J. Williams, Chem.-Eur. J., 2003, 9, 543; (b) S. A. Vignon, J. Wong, H.-R. Tseng and J. F. Stoddart, Org. Lett., 2004, 6, 1095. 
13 (a) Y. Liu, S. A. Vignon, X. Zhang, K. N. Houk and J. F. Stoddart, Chem. Commun., 2005, 3927; (b) C. Reuter, A. Mohry, A. Sobanski and F. Vögtle, Chem.-Eur. J., 2000, 6, 1674.

14 (a) W. Zhang, A. Abdulkarim, F. E. Golling, H. J. Räder and K. Müllen, Angew. Chem., Int. Ed., 2017, 56, 2645; (b) T. Prakasam, M. Lusi, M. Elhabiri, C. Platas-Iglesias, J.-C. Olsen, Z. Asfari, S. Cianférani-Sanglier, F. Debaene, L. J. Charbonnière and A. Trabolsi, Angew. Chem., Int. Ed., 2013, 52, 9956; (c) N. C. Habermehl, D. J. Eisler, C. W. Kirby, N. L.-S. Yue and R. J. Puddephatt, Organometallics, 2006, 25, 2921.

15 (a) A. Bogdan, M. O. Vysotsky, T. Ikai, Y. Okamoto and V. Böhmer, Chem.-Eur. J., 2004, 10, 3324; (b) O. Molokanova, A. Bogdan, M. O. Vysotsky, M. Bolte, T. Ikai, Y. Okamoto and V. Böhmer, Chem.-Eur. J., 2007, 13, 6157.

16 (a) R. Katoono, Y. Obara, K. Kusaka and T. Suzuki, Chem. Commun., 2018, 54, 735; (b) R. Katoono, S. Kawai and T. Suzuki, Chem. Sci., 2016, 7, 3240.

17 (a) A. L. Sadowy and R. R. Tykwinski, in Modern Supramolecular Chemistry: Strategies for Macrocycle Synthesis, ed. F. Diederich, P. J. Stang and R. R. Tykwinski, Wiley-VCH Verlag GmbH \& Co. KGaA, Weinheim, 2008, ch. 6, pp. 185-231; (b) C. S. Jones, M. J. O'Connor and M. M. Haley, in Acetylene Chemistry. Chemistry, Biology and Material Science, ed. F. Diederich, P. J. Stang and R. R. Tykwinski, Wiley-VCH Verlag GmbH \& Co. KGaA, Weinheim, 2005, ch. 8, pp. 303-385.

18 (a) J. Zhang, D. J. Pesak, J. L. Ludwick and J. S. Moore, J. Am. Chem. Soc., 1994, 116, 4227; (b) H. A. Staab and K. Neunhoeffer, Synthesis, 1974, (6), 424.
19 Z. Wu, S. Lee and J. S. Moore, J. Am. Chem. Soc., 1992, 114, 8732.

20 (a) C. O. Dietrich-Buchecker and J.-P. Sauvage, J. Am. Chem. Soc., 1984, 106, 3043; (b) D. G. Hamilton, J. E. Davies, L. Prodi and J. K. M. Sanders, Chem.-Eur. J., 1998, 4, 608; (c) M. J. Langton, J. D. Matichak, A. L. Thompson and H. L. Anderson, Chem. Sci., 2011, 2, 1897; (d) G. Götz, X. Zhu, A. Mishra, J.-L. Segura, E. Mena-Osteritz and P. Bäuerle, Chem.-Eur. J., 2015, 21, 7193.

21 (a) C. Schweez and S. Höger, Chem.-Eur. J., 2018, 24, 12006; (b) Ö. Ünsal and A. Godt, Chem.-Eur. J., 1999, 5, 1728; (c) S.-H. Li, H.-Y. Zhang, X. Xu and Y. Liu, Nat. Commun., 2015, 6, 7590.

22 In a preliminary synthetic trial, we confirmed that a set of four products 1-4 were obtained from an approx. $1: 1$ mixture of $\mathbf{9 a}$ and $\mathbf{9 b}$.

23 It was impossible to separate the racemates 4 even though we tried many conditions with several columns and eluents: CHIRALPAK IA, IB, IC, ID, IE, IF, IG and IH, commercially available from DAICEL Co., Japan.

24 S. Akine, TitrationFit, program for analyses of host-guest complexation, Kanazawa University, Kanazawa, Japan, 2013.

25 Below room temperature, Cotton effects were slightly attenuated (Fig. S6c $\dagger$ ). This was a specific case for highlyflexible model 13. This result suggested that higherordered complexation through hydrogen bonding was preferred at lower temperatures to reach a situation similar to that in the presence of abundant equivalents of guest.

26 (a) J. C. Nelson, J. G. Saven, J. S. Moore and P. G. Wolynes, Science, 1997, 277, 1793; (b) R. B. Prince, S. A. Barnes and J. S. Moore, J. Am. Chem. Soc., 2000, 122, 2758. 